\title{
MATA CILIAR E AS NASCENTES NO MUNICÍPIO DE SAPUCAIA DO SUL - RS SOB O OLHAR DA EDUCAÇÃO AMBIENTAL
}

\author{
André Luis Demichei', Toshio Nishijima² \\ ${ }^{1}$ Especialista em Educação Ambiental \\ ${ }^{2}$ Prof. Dr., DER/UFSM
}

\section{RESUMO}

O presente trabalho teve por objetivo geral verificar as condições de conservação de algumas nascentes e suas matas ciliares juntamente analisar o conhecimento de alunos da modalidade EJA e confrontar com práticas de Educação Ambiental que promovam ou que deixam de promover cansando impactos ao meio ambiente. Foi levantado um referencial teórico acerca da problemática em questão, no caso mata ciliar e nascentes, onde como fonte de estudo no município foi utilizado a RPPN Morro de Sapucaia, onde existem 5 nascentes. Foi-se analisado in loco estas nascentes e seu estado de conservação, juntamente com alunos e confrontado com um curso de água que cruza a área urbanizada, curso este que possui suas nascentes na RPPN, observado o impacto que sofre com a ação humana. Também foi aplicado um questionário para alguns professores e alunos contendo 10 questões que deveriam ser respondidas de forma qualitativa, sem a interferência do pesquisador. Fica claro que as práticas de Educação Ambiental não estão sendo atingidas, portanto não há uma real capacidade de propagação destas ideias, pois não basta o conhecimento sobre o assunto é preciso aplicá-lo.

Palavras-chave: Educação Ambiental; mata ciliar; nascentes; EJA.

\section{ABSTRACT}

This study had to aim verify the general conditions of conservation of some springs and its riparian areas along to analyze the knowledge the way of adult education students and confront practices that promote environmental education or that fail to promote causing impacts on the environment. It was raised a theoretical framework regarding the problem in question, if riparian vegetation and water sources, where like a source of study in the town was used "Morro de Sapucaia" PRNP, where there are three springs. It was analyzed in situ these springs and their conservation status, along with students and faced with a stream that crosses the urbanized area, this course which has their sources in the PRNP, noted the impact that suffers from human action. Also a questionnaire was administered for some teachers and students containing 10 questions that should be answered in a qualitative way, without interference from researcher. It is clear that the practices of environmental education are not being met, so there isn't real capacity to spread these ideas, it is not enough knowledge about the subject, it is need to apply it.

Key words: Environmental Education; riparian forest; springs; adult education. 


\section{INTRODUÇÃO}

Sapucaia do Sul é um município de inúmeras riquezas naturais que na maioria das vezes são pouco exploradas e que devem ser reconhecidas e aproveitadas, pois elas é que promovem para a população uma melhor harmonia entre homem e meio; como o município faz parte da região metropolitana de Porto Alegre e está atravessado pela rodovia federal BR-116, temos um processo de industrialização e consequente urbanização muito forte, este processo traz vantagens econômicas para o município como um grande número de empregos que disponibiliza um forte acréscimo da arrecadação em impostos, mas também traz um lado muito cruel no que diz respeito ao meio ambiente porque essas mesmas indústrias que elevam o lado econômico também poluem muito e muitas vezes sem se preocupar com a natureza, quer dizer sem o devido respeito as questões ambientais, por esses motivos e outros aqui não citados é que faz nos preocupar com algo que possa amenizar este estresse ambiental e, dentre elas, encontramos o Morro Sapucaia, Reserva Particular de Patrimônio Nacional - RPPN, abundante em nascentes que preservadas promoverão o desenvolvimento econômico sustentável, garantindo maior qualidade de vida aos seus habitantes.

\section{Objetivo geral}

Este trabalho teve como objetivo geral desenvolver a consciência de proteção, preservação e recuperação das nascentes e matas ciliares do Morro Sapucaia do Sul que circundam e perpassam o bairro Capão da Cruz, no município de Sapucaia do Sul no Rio Grande do Sul, estabelecendo vínculos de cooperação e colaboração com a comunidade.

\section{Objetivos específicos}

a) Reconhecer as nascentes e as matas ciliares com suas espécies nativas do Morro Sapucaia do Sul e áreas adjacentes, identificando áreas de degradação;

b) Estabelecer vínculos de cooperação e colaboração, aproximando escola e comunidade em geral para o desenvolvimento sustentável e possível conscientização para a proteção e recuperação das matas ciliares e a conservação das nascentes;

c) Oportunizar aos alunos da EJA aplicar os conhecimentos escolares e tornarem-se multiplicadores da consciência preservacionista.

\section{REVISÃO BIBLIOGRÁFICA}

Água, matas e fauna são indissociáveis. A vegetação, por ser diretamente relacionada à permeabilidade dos solos, é determinante para a regularidade da vazão dos rios. A relação é ainda mais clara quando se trata daquela que ladeia os cursos d'água - a mata ciliar, estabilizando as margens, impedindo a erosão e o assoreamento dos cursos hídricos, entre tantas outras funções importantes (SMA, 2009, p. 5).

A mata que se forma às margens dos rios também serve de abrigo aos animais, que podem se reproduzir ali e também se alimentar dessas plantas. Esses animais também podem utilizar a mata ciliar como um corredor entre florestas distantes entre si, sem precisar cruzar campos cultivados e, com isso, arriscar a vida. Os peixes também acabam se servindo das árvores, que 
fornecem alimento e criam na região do rio um clima onde são menores as variações de temperatura (NASS, 2002).

Matas ciliares são formações vegetais que se encontram associadas aos corpos d'água, independente de sua área ou região de ocorrência, bem como sua composição florística. Também conhecida como mata galeria, mata de várzea, vegetação ripária e formação ribeirinha. É uma área extremamente importante para o desenvolvimento dos processos ambientais. Levando-se em conta a integridade da micro bacia hidrográfica, as matas ciliares ocupam as áreas mais dinâmicas da paisagem, tanto em termos hidrológicos, como ecológicos e geomorfológicos (SEMA, 2007).

Assim como os cílios protegem os olhos, a mata ciliar protege as nascentes, córregos e rios. O termo Mata Ciliar significa qualquer formação florestal na margem de cursos d'água. As Matas Ciliares foram reduzidas drasticamente e, quando presentes, normalmente são vestígios (WWFBrasil, 2006 p. 16).

As formações ribeirinhas sempre foram alvo de todo tipo de degradação, basta considerar que muitas cidades foram fundadas às margens de cursos d'água que, em muitos casos, cederam o seu lugar para a construção de hidrelétricas, empresas de saneamento e estradas bem como forneceram acesso ao gado, o qual acabou degradando dos solos e causando dificuldades de regeneração natural. Um ecossistema torna-se degradado quando perde sua capacidade de recuperação natural após distúrbios. Para o êxito de restauração de matas ciliares é necessário avaliar a topografia, clima, regime hídrico, tipo de solo, fertilidade natural e graus de degradação. O grau de preservação de matas ciliares é considerado de fundamental importância, pois é um indicador da qualidade dos ambientes associados aos recursos hídricos superficiais naturais (SEMA, 2007 p. 14).

Para a retirada de vegetação é preciso uma autorização e esta somente será concedida de acordo com a Resolução Conama no 369, de 28/3/2006 (CONAMA), que regulamenta este assunto, dispondo sobre os casos quando é possível a intervenção ou supressão de vegetação em Área de Preservação Permanente (APP) em caso de:

- utilidade pública,

- interesse social ou

- baixo impacto ambiental.

Esta recuperação de matas ciliares e a sua conservação assim como a conservação de nascentes são de fundamental importância para que se possa interligar e proteger partes da fauna que está em risco ou quase extinta. A fauna silvestre requer um habitat no qual lhe de uma relativa segurança para que possa procriar e circular, mantendo assim o equilíbrio ambiental, tanto da população como da biodiversidade.

Entende-se por nascente o afloramento do lençol freático que vai dar origem a uma fonte de água de acúmulo (represa), ou cursos d'água (regatos, ribeirões e rios). As nascentes, cursos d'água e represas, embora distintos entre si por várias particularidades quanto às estratégias de preservação, apresentam como pontos básicos comuns o controle da erosão do solo por meio de estruturas físicas e barreiras vegetais de contenção, minimização de contaminação química e biológica e ações mitigadoras de perdas de água por evaporação e consumo pelas plantas (SMA, 2009). 
As nascentes localizam-se em encostas ou depressões do terreno, ou ainda, no nível de base representado pelo curso d'água local; podem ser perenes (de fluxo contínuo), temporárias (de fluxo apenas na estação chuvosa) e efêmeras (surgem durante a chuva, permanecendo por apenas alguns dias ou horas) (CALHEIROS, 2004).

A degradação ambiental gerada pela falta de investimentos em coleta e tratamento de esgotos tem levado a crescente poluição dos recursos hídricos superficiais e subterrâneos por carga orgânica e nutrientes. Como consequências, têm-se a redução da disponibilidade do recurso e o aumento dos custos de tratamento para fins de abastecimento público. A médio e longo prazo tem-se o comprometimento dos recursos hídricos para gerações futuras e a destruição de ecossistemas dependentes destes recursos. Portanto, a internalização dos custos de tratamento, recuperação e preservação dos recursos deve ser um objetivo do sistema de gestão (RAMOS, 2007 apud NIEDERAUER, 2007).

Deste modo, é indispensável o papel da educação ambiental, na formação de uma sensibilidade conservacionista, pois só assim será possível uma gestão de recursos hídricos eficaz. Assim no momento em que pessoa sente-se inserida no ambiente em que vive agirá de forma consciente.

A chamada "desconexão de habitats" está sendo considerada por biólogos brasileiros como uma das principais causas do declínio de anfíbios. Acostumados a viverem em florestas com acesso fácil à água para o período de desova e nascimento dos filhotes, eles não estão lidando bem com as intervenções do homem que acabaram dividindo seu habitat (BECKER et al. 2007).

De acordo com Rangel (2007), a mata ciliar atua como um corredor ecológico, que possibilita que indivíduos isolados em fragmentos possam deslocar-se até outro fragmento, garantindo a sustentabilidade de espécies vegetais e animais em suas relações naturais (Figura 1). A mata propicia o fluxo gênico, ou seja, a interação de indivíduos da mesma espécie, mas de comunidades diferentes. "Sem este fluxo, pode ocorrer um empobrecimento genético e declínio no número de espécies". (RANGEL, 2007) ${ }^{1}$

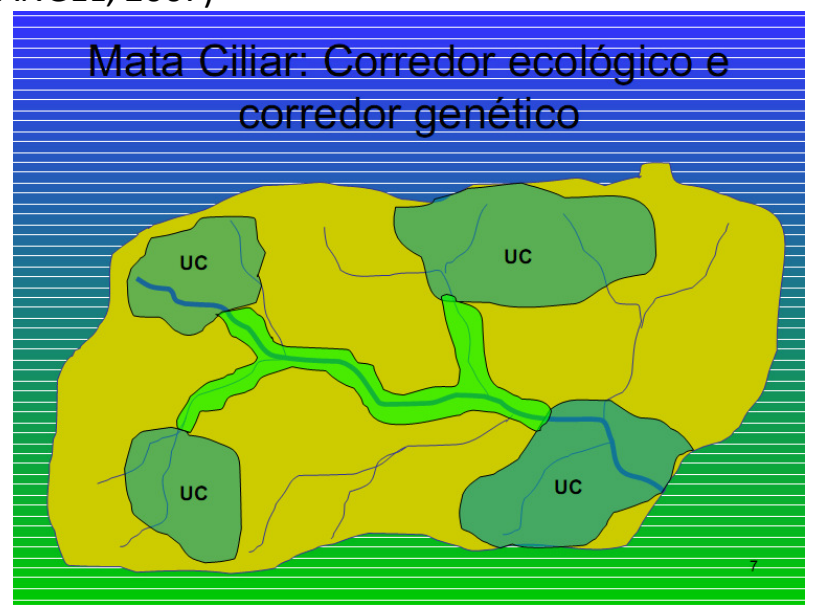

Figura 1 Corredor ecológico e genético ligando Unidades de Conservação. Fonte: www.ciliosdoribeira.org.br

\footnotetext{
${ }^{1}$ Extraido da página da internet <http://www.ciliosdoribeira.org.br/pt-br/import-ncia-de-recuperar> .Acesso em: 20/12/2010.
} 
Segundo CARVALHO (2004) a Educação Ambiental pode se transformar em uma importante mediadora entre a esfera educacional e o campo ambiental, dialogando com os novos problemas gerados pela crise ecológica e produzindo reflexões, concepções, métodos e experiências que visam construir novas bases de conhecimento e valores ecológicos nestas e nas futuras gerações. A legitimação deste conjunto de preocupações e práticas ambientais na sociedade contemporânea é o terreno fértil em que podemos ver surgir um sujeito ecológico e de fácil trâmite entre as diferentes áreas.

Tem-se que:

\begin{abstract}
A EA surge em um terreno marcado por uma tradição naturalista. Superar esta marca, mediante a afirmação de uma visão socioambiental, exige um esforço de superação da dicotomia entre natureza e sociedade. A visão socioambiental orienta-se por uma racionalidade complexa e interdisciplinar e pensa o meio ambiente não como sinônimo de natureza intocada, mas como um campo de interações entre a cultura, a sociedade e a base física e biológica dos processos vitais (CARVALHO, 2004, p 37).
\end{abstract}

Para aprender a problemática ambiental, é necessário uma visão complexa de meio ambiente, em que a natureza integra uma rede de relações não apenas naturais, mas também sociais e culturais.

Leff (1998) criou a expressão Saber Ambiental para designar o saber que desponta da racionalidade científica para entender a complexidade das interações entre sociedade e natureza.

Considera-se que:

O saber ambiental problematiza o conhecimento fracionado em disciplinas e a administração setorial do desenvolvimento, para constituir um campo de conhecimentos teóricos e práticos orientado para a rearticulação das relações sociedade-natureza. O saber ambiental transborda o campo das ciências ambientais.(LEFF,1998, p.124).

Para atingir os seus objetivos um processo de educação ambiental deve se munir de características que permitam uma abordagem ampla o bastante para incorporar a complexidade de conteúdos ecológicos, morais, socioculturais políticos e psicológicos uma vez que os problemas ambientais não são desvinculados desse aspecto (HIGUCHI, 2003 apud NIEDERAUER, 2007).

A Educação Ambiental não pode ser abordada apenas em sua dimensão local. O ambiente pode ser compartilhado por diferentes povos e nações. Por exemplo, se um lençol freático for contaminado em um bairro de uma cidade e dele aflorar um riacho em outra localidade a contaminação química, se expandirá. Ou mesmo uma indústria que libere efluentes líquidos contaminados em rios poderá alterar as condições de solo e da água de outros municípios, estado, ou país que não tenha aquela indústria. Por isso é que existem acordos internacionais, pois a degradação ambiental não obedece fronteiras (PEDRINI, 1997).

Ainda Carvalho (2004) a Educação Ambiental rompe a barreira da educação formal para uma atuação não formal pois além dela estar presente nos ambientes escolares com crianças e jovens, está presente também entre os adultos, agentes locais, moradores e lideres comunitários. 
A preocupação com os problemas ambientais locais ajuda a criar um novo espaço de relações entre a escola, a comunidade e a realidade socioambiental que as envolve. A Educação Ambiental pretende provocar processos de mudanças sociais e culturais que visam promover a sensibilização da sociedade quanto a crise ambiental e a urgência na mudança de padrões de uso dos bens ambientais.

Há uma diferença entre atitude e comportamento de um indivíduo pois o mesmo pode ter determinada atitude, para agradar a outrem que a ele deva resposta, mas longe deste ter comportamento contrário; isto quer dizer que o indivíduo pode saber o certo e o errado, o como fazer para uma Educação Ambiental correta, em forma de atitudes em determinado ambiente mas, em seu ambiente familiar ou vínculo social ter um comportamento dissociado.

Temos que:

A crise ambiental é a crise do nosso tempo. O risco ecológico questiona o conhecimento do mundo. Esta crise se apresenta a nós como um limite no real que re-significa e reorienta o curso da história: limite do crescimento econômico e populacional; limite dos desequilíbrios ecológicos e das capacidades de sustentação da vida; o limite da pobreza e da desigualdade social (LEFF, 2003, p. 15).

Deste modo, é indispensável o papel da educação ambiental, na formação de uma sensibilidade conservacionista, pois só assim será possível uma gestão de recursos hídricos eficaz. Assim no momento em que pessoa sente-se inserida no ambiente em que vive agirá de forma consciente.

A educação ambiental é um instrumento potencialmente eficiente para se reorientar a relação do homem com o meio em que vive, de forma que esta possa ser inclinada para a participação social e para a solução de problemas ambientais desenvolvendo, desta forma, uma mudança substancial de valores, atitudes e comportamentos sociais (NIEDERAUER, 2007)

Conforme o direito ao meio ambiente:

O bem ambiental não pode ser rotulado como bem público, devendo, sim, ao contrário, ser considerado um bem de interesse público e cuja administração, uso e gestão devem ser compartilhados e solidários com toda a comunidade, inspirado em um perfil de democracia ambiental. Desta forma, no Estado democrático ambiental, o bem ambiental deve pertencer à coletividade e não integra o patrimônio disponível do Estado, impedindo o uso irracional e autoritário de patrimônio ambiental pelo poder público e pelo particular (LEITE, 2000, p. 21).

A propósito:

É inegável que atualmente estamos vivendo uma intensa crise ambiental, proveniente de uma sociedade de risco, deflagrada, principalmente, a partir da constatação de que as condições tecnológicas, industriais e formas de organização e gestões econômicas da sociedade estão em conflito com a qualidade de vida. Parece que esta falta de controle da qualidade de vida tem muito a ver com a racionalidade do desenvolvimento econômico do Estado, que marginalizou a proteção do meio ambiente (LEITE, 2000, p. 13). 
Os termos preservação, conservação e recuperação do sistema dos mananciais devem ser prioritárias para a manutenção da boa qualidade e quantidade das águas, com a finalidade de garantir a sobrevivência humana.

Deste modo, o surgimento de uma consciência ambiental não pode ser estabelecido por uma disciplina específica de meio ambiente, ou por qualquer nível de ensino que seja inserido, já que tem que fazer parte de um contexto maior, a educação do ser humano.

A educação ambiental deve ajudar a desenvolver uma consciência ética sobre todas as formas de vida com as quais compartilhamos este planeta, respeitar seus ciclos vitais e impor limites à exploração dessas formas de vida pelos seres humanos.

\section{METODOLOGIA}

Em relação à Educação Ambiental nas escolas, a preparação do aluno é importante sob o ponto de vista intelectual e afetivo. A passagem do estudante pela escola efetiva-se geralmente no instante ideal para conscientizar o educando sobre o problema ambiental e integrá-lo nas pesquisas do meio e suas riquezas. Além disso, a escola deverá esclarecê-lo e sensibilizá-lo sobre os conceitos do meio ambiente natural e os riscos da degradação ambiental. O estudo quando feito sob uma pesquisa reativa, consequentemente desenvolverá no estudante um enfoque próativo, o qual será resultante de suas reflexões críticas a respeito da sua capacidade para mudar a realidade ambiental (BUSTOS, 2003).

A pesquisa qualitativa considera que há uma relação dinâmica entre o mundo real e o sujeito, isto é, um vínculo indissociável entre o mundo objetivo e a subjetividade do sujeito que não pode ser reduzido apenas em números. A interpretação dos fenômenos e a atribuição de significados são básicas no processo de pesquisa qualitativa.

O estudo utiliza a legislação vigente brasileira para poder defrontar com o que pode ou não pode ser feito em termos preservacionistas. Uma análise que leva em conta o papel da vegetação e dos cursos d'água para a conservação e preservação da biodiversidade e dos recursos naturais.

Foram analisados os conhecimentos acerca dos alunos, pertencentes a modalidade Educação de Jovens e Adultos (EJA) da E.M.E.F. Padre Reus do município de Sapucaia do Sul, sobre a importância da Reserva Particular do Patrimônio Natural (RPPN) Morro de Sapucaia e a sua consequente forma de promover a Educação Ambiental.

Através, primeiramente da abordagem com a exposição dos principais problemas urbanos enfrentados pela população, foi-se discutido quem eram os principais causadores daqueles eventos e se eles se visualizavam em alguns dos casos relatados na apresentação.

Foi utilizado um trabalho de multimídia, no qual problemas ambientais frequentes na sociedade são explicitados. Após a visualização foi apresentado aos alunos um questionário acerca do conhecimento e do que fazem para promover a melhoria de nosso planeta. Também no questionário foram identificados fatores locais a respeito da RPPN Morro de Sapucaia, o que sabem sobre ela e qual a importância dela para a preservação do meio ambiente.

Como ponto de análise utilizou-se a RPPN Morro de Sapucaia, no município de Sapucaia do Sul, área que foi criada com o objetivo de conservar e recuperar a biodiversidade de ecossistemas em seu estado natural, protegendo e promovendo o patrimônio cultural da área. 


\section{REMOANFSM}

No entorno da RPPN encontra-se localizado um aterro industrial, onde nele são depositados resíduos industriais e hospitalares; o trânsito dos caminhões ocorre por dentro da reserva ocasionado muitos problemas principalmente para a fauna visto que estes caminhões provocam muito barulho e também muitos animais são atropelados e mortos na estrada.

A RPPN Fazenda Morro Sapucaia apresenta importantes valores ambientais, sociais e culturais, fatores estes que a consagram como Unidade de conservação. Sua função é mais do que assegurar que a fauna e a flora local sejam preservadas. A principal contribuição é a preservação de um remanescente vegetal que pertence a um dos ecossistemas mais ameaçados do mundo, o bioma Mata Atlântica, o qual engloba a formação Floresta Estacional.

Em parceria com a Escola Ambiental do município e com a Dra. Ana Juliano, proprietária do Morro e a equipe multidisciplinar da escola, as pesquisas iniciaram-se em 2009 com os alunos da EJA, inclusive com saída de campo documentada (figura 2).

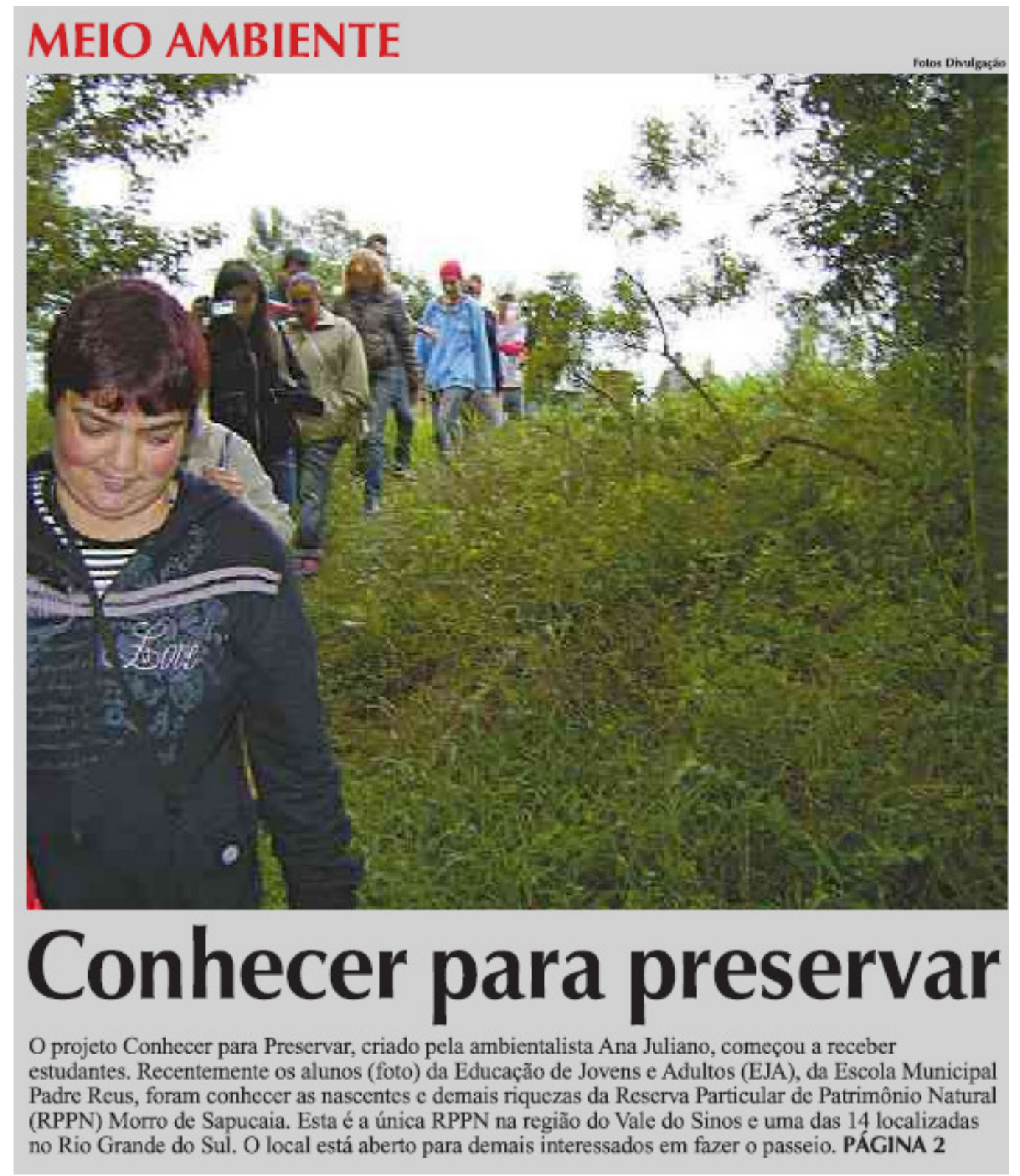


FIGURA 2-Reportagem do jornal VS Vale dos Sinos do dia 10/06/2010 ressaltando o quanto é importante conhecer para poder preservar. A reportagem mostra uma saída ao Morro de Sapucaia por alunos de EJA da E.M.E.F. Padre Reus promovida pelo professor de Geografia André Luis Demichei.

O comprometimento e a motivação de todos, considerando-se que possa vir a ser um projeto permanente dentro do município, desmembrando-o em outros segmentos, como conservação de solos, captação de energia eólica, solar, etc. a pesquisa inicia-se com a criação de um núcleo, com trabalho de base de conscientização evoluindo para a preservação e recuperação, com pouco investimento inicial como micro-ônibus para saídas de campo; mapa das nascentes do município; mapa político do município; análises de água das nascentes a serem coletadas, apresentação multimídia explicitando problemas persistentes no município de Sapucaia do Sul.

\section{Questionário qualitativo:}

O questionário foi elaborado de forma com que professores e alunos pudessem expor de forma qualitativa e espontânea a sua concepção de meio ambiente, de degradação e a sua importante preservação como forma de mantermos uma qualidade de vida futura. Este questionário foi aplicado de maneira que estes alunos e professores pudessem refletir sobre suas colaborações sem a influência do pesquisador.

Os professores e alunos são da modalidade EJA da E.M.E.F. Padre Reus, no município de Sapucaia do Sul. São todos integrantes do ensino noturno e pertencentes as etapas finais do ensino fundamental, alunos estes que estão numa faixa etária que vai dos 15 anos aos 60 anos.

Este questionário foi entregue aos participantes entre os dias 08 e 12 de agosto e devolvido na semana seguinte sem o compromisso e obrigação de participação, portanto deveria ser feito de forma espontânea e consciente buscando o conhecimento destes acerca dos assuntos relacionados ao meio ambiente, a sua conservação e consequente preservação. Estes alunos residem todos nas áreas em torno do objeto de estudo e isto pode levar a um maior conhecimento da área e dos problemas.

\section{RESULTADOS E DISCUSSÃO}

A aplicação do questionário foi realizada com 9 professores e 31 alunos das séries finais da modalidade EJA; destes, 5 professores e 21 alunos retornaram as questões e 4 professores e 10 alunos não participaram da pesquisa, tendo uma adesão efetiva ao projeto de $55 \%$ dos professores e $68 \%$ dos alunos (pesquisa esta realizada no mês de agosto de 2011).

Foram aplicadas as seguintes perguntas para professores e alunos: 1-O que você entende por meio ambiente? 2-Você acha importante preservá-lo? Por quê? 3-Você sabe o que são mata ciliar e nascentes? 4-Você acha importante para o meio ambiente preservar mata ciliar e nascentes? Se a resposta for sim, diga por quê? 5-Você colabora na conservação do meio ambiente? Se a resposta for sim diga de que maneira. 6-Você conhece a RPPN Morro de Sapucaia? Sabe para o que ela serve? 7-Você sabe qual a sua importância para o município de Sapucaia do Sul? 8-Você já participou de algum projeto que ajude a preservar o meio ambiente? Se sim, diga qual? 9-Você causa algum dano ao meio ambiente no seu dia-a-dia? Se a resposta for sim, diga de que forma? 10-Qual mudança de atitude que você pode tomar no seu cotidiano que poderá beneficiar o meio ambiente? 
O questionário foi aplicado de forma que tanto professores quanto alunos pudessem responder sem que houvesse interferência do pesquisador, portanto de forma qualitativa, apenas coletando o conhecimento que ambos os grupos possuíam a respeito de questões ambientais.

\section{Discussões}

Através dos resultados do questionário buscou-se o objetivo de sensibilizar alunos, professores e comunidade a respeito de criar-se a consciência quanto a importância da preservação e conservação do planeta e também da igualdade social. É uma educação ambiental comprometida com a transformação da realidade rumo a sustentabilidade socioambiental e percebe-se o ambiente educativo como movimento, mas um movimento aderido ao da realidade socioambiental, onde se contextualiza. Assim, acredita-se que, para atingir seus objetivos, um processo de educação ambiental deve se munir de características que permitam uma abordagem ampla o bastante para incorporar a complexidade de conteúdos ecológicos, morais, socioculturais, políticos e psicológicos, uma vez que os problemas ambientais não são desvinculados desses aspectos.

Como aspecto negativo, em relação à área de estudo observa-se em primeiro lugar a circulação clandestina relativamente grande de pessoas na área com fins não associados às atividades ambientais, o que afeta diretamente o uso potencial da área como unidade de conservação. A primeira consequência disso é a deposição de lixo em diversos pontos da estrada e da área. Também a segurança é afetada devido à circulação de pessoas com interesses escusos, tais como uso de tóxicos, fuga da lei, etc. A vegetação também é diretamente afetada pelo pisoteio, quebra de galhos, coleta e remoção do hábitat. Muitos frequentadores possuem o hábito de fazer inscrições em rochas e troncos de árvores. De forma mais específica, o uso da área para rituais religiosos, de diferentes correntes, tem contribuído para a deterioração ambiental, causando também os efeitos citados acima. Outrossim, podemos afirmar que tais aspectos negativos são propiciados pelo ingresso na área da Reserva pela Estrada que à atravessa (Estrada Cristina Juliano), ressaltando-se que o leito da estrada é parte integrante da área da reserva e não público.

Outro aspecto negativo tem-se na circulação de grande quantidade de veículos, a maioria de grande porte, na via de acesso que atravessa a RPPN, (Estrada Particular Cristina Juliano), e que dirigem-se ao aterro industrial da empresa Multtiserviço Tecnologia Ambiental Ltda, causam poluição sonora em níveis altos, que afetam principalmente a fauna (o que pode ter consequências indiretas para a flora, como por exemplo, a diminuição de polinizadores e dispersores). Juntamente com os ruídos, o trânsito provoca atropelamento da fauna e eleva bastante a poeira em suspensão, que acaba se depositando sobre a vegetação.

Os resultados obtidos com a aplicação do questionário proporcionaram avaliar o conhecimento dos alunos e professores em relação ao Meio Ambiente e/ou Educação Ambiental e também poder avaliar o seu comprometimento em ajudar nesta busca para um equilíbrio ambiental como a sua contribuição. Também foi importante para poder compreender como alunos e professores entendem e compreendem o meio ambiente e qual contribuição podem dar para a manutenção da qualidade de vida do lugar em que vivem.

\section{CONCLUSÕES}


O trabalho permitiu o reconhecimento das nascentes e as matas ciliares com suas espécies nativas do Morro Sapucaia do Sul e áreas adjacentes. Verificou-se que são abrigados 319 espécies vegetais pertencentes a 89 famílias, entre elas, araticum, butiazeiro, barba-de-pau, figueiravermífuga, figueira-da-folha-miúda, pitangueiras, café do mato, ameixeiras, entre outras. Na parte de animais, graxains, preás, mão pelada, e tatus, além de répteis, anfíbios e pássaros como picapau-dourado, dançador, anambé-branco-de-rabo-preto, vira-folha, gavião, urubus, sabiá-ferreiro, canarinho-da-terra, entre outros. O morro também possibilita vista panorâmica da região metropolitana. Outro destaque do local é a imensa quantidade de ervas medicinais e a presença de cinco nascentes.

Foi reconhecida a nascente do arroio José Joaquim, arroio que cruza o centro da cidade de Sapucaia do Sul e que nasce no interior do Morro Sapucaia. Além de observar-se a mata ciliar que protege esta nascente, mata esta que faz parte de resquícios da Mata Atlântica, observa-se a qualidade em que encontra-se as suas águas. $O$ estado de conservação das nascentes e sua mata ciliar encontram-se em muito bom estado no interior da RPPN Morro de Sapucaia. Já o arroio José Joaquim em seu curso mais à jusante encontra-se em um estado de degradação avançado pois teve sua mata ciliar totalmente retirada, o curso canalizado além de se constituir em um verdadeiro depósito de lixo.

Os vínculos de cooperação e colaboração, buscando a aproximação escola e comunidade em geral para o desenvolvimento sustentável e possível proteção e recuperação das matas ciliares e a conservação das nascentes foram observados. Com a participação dos alunos da modalidade EJA, através do uso de material multimídia foi possível apresentar os problemas que a não conservação de nascentes e mata ciliar podem provocar na comunidade. Através destas abordagens pode-se observar nos alunos uma interação e um interesse de mudanças muito grande. Constatou-se que alunos concluem que grande parte dos culpados pelo péssimo estado que se encontra os cursos são eles próprios, que a população em grande parte das vezes destrói o ambiente em que vivem.

Através de discussões em sala de aula, debates nas apresentações à respeito do projeto, aplicação de questionário, foi-se integrado a teoria à prática, com as saídas de campo. Os alunos passaram a observar de maneira diferente o lugar em que vivem, pois os problemas que antes pareciam não os prejudicar, agora os deixam muito preocupados principalmente em se tratando da qualidade da água do Rio dos Sinos, de onde é extraída a água que bebem e utilizam para os afazeres domésticos.

Após a realização deste trabalho, pode-se concluir que a interação entre comunidade e escola é possível a partir do momento em que o conhecimento pode ser contextualizado e servir de real necessidade da população em busca da qualidade de vida.

\section{REFERÊNCIAS BIBLIOGRÁFICAS}

BECKER, C. G. et al. Habitat split and the global decline of amphibians. vol. 318, págs. 1775-1777, 2007. Disponível em: www.sciencemag.org acesso em 07/07/2011. Artigo científico publicado no jornal folha Online em 14/12/2007 por Giovana Girardi. 
BRASIL, Cadernos de Educação Ambiental. Água para Vida, Água para Todos: Livro das Águas / Andrée de Ridder Vieira texto: Larissa Costa e Samuel Roiphe Barrêto coordenação - Brasília: WWF, 2006.

BUSTOS, M. R. L. A Educação Ambiental sob a ótica da gestão de recursos hídricos. São Paulo, 2003. Tese de doutorado. Escola Politécnica da Universidade de São Paulo. Departamento de Engenharia Hidráulica e Sanitária.

CALHEIROS, R. de O. et al. Preservação e recuperação de nascentes. Comitê das bacias hidrográficas dos Rios PCJ-CTRM, Piracicaba, São Paulo,2004. Disponível em: http://ambiente.sp.gov.br/mataciliar acesso em 01/07/2010.

CARVALHO, I. C. de M. Educação Ambiental: a formação do sujeito ecológico. São Paulo: Cortez, 2004.

CONAMA. Legislação ambiental. Disponível em http://www.mma.gov.br/conama. Acesso em 12 de dezembro de 2010.

LEFF, E. (Coord.). A complexidade ambiental. São Paulo: Cortez, 2003.

Saber ambiental: sustentabilidad, racionalidad, complejidad,

poder. México: Siglo XXI ed/PNUMA; 1998.

LEITE, J. R. M. Inovações em Direito Ambiental. Florianópolis: Fundação Boiteux, 2000.

NASS, D. P. Mata ciliar: corredor da natureza. São Paulo. Instituto de Química de São Carlos da Universidade de São Paulo, 2002. Disponível em: < http://www.cdcc.usp.br/ciencia/artigos/art 14/mataciliar.html>. Acesso em 08/05/2011.

NIEDERAUER, P. D. P. Educação ambiental como sustentáculo da gestão de recursos hídricos no Brasil. Santa Maria, UFSM, 2007.

PEDRINI, A. de G. Trajetórias da Educação Ambiental. In reflexões e práticas contemporâneas. Petropolis: Vozes, 1997.

(Org.). Educação ambiental:

RANGEL, J. C. A importância de recuperar. 2007. Disponível em: <http://www.ciliosdoribeira.org.br/pt-br/import-ncia-de-recuperar> . Acesso em: 20/12/2010.

RIO GRANDE DO SUL. Diretrizes ambientais para restauração de matas ciliares. Porto Alegre. Departamento de Florestas e Áreas Protegidas. SEMA, 2007.

SMA, SECRETARIA DE ESTADO DE MEIO AMBIENTE. Departamento de Proteção da Biodiversidade. Cadernos da Mata Ciliar - N 1 (2009)--São Paulo, 2009. 